\title{
Haemodynamic effects of salbutamol and nitroprusside after cardiac surgery
}

\author{
P. A. POOLE-WILSON,1 G. LEWIS, T. ANGERPOINTER, A. D. MALCOLM, \\ AND B. T. WILLIAMS
}

\begin{abstract}
From the Department of Cardiothoracic Surgery and the Intensive Care Unit, St. Thomas's Hospital, London
\end{abstract}

The haemodynamic effects of a continuous intravenous infusion of salbutamol (15 to $30 \mathrm{\mu g} / \mathrm{min}$ ) and nitroprusside (50 to $100 \mathrm{\mu g} / \mathrm{min}$ ) were compared in 9 patients after cardiac surgical operations. The mean falls in left atrial pressure and systemic vascular resistance were similar with the two drugs but salbutamol caused a greater increase in heart rate, maximum acceleration of aortic blood flow, and maximum rate of change of left ventricular power. Because these differences would cause greater myocardial oxygen consumption with salbutamol and because the infusion of salbutamol is less easily controlled, nitroprusside is the preferred drug after cardiac operations.

Drugs that cause vasodilatation and consequently a reduction in systemic vascular impedance (left ventricular afterload) have recently been advocated in a variety of circumstances in which cardiac function is abnormal. Advantageous effects have been reported in patients with acute myocardial infarction (Chatterjee et al., 1973), chronic ischaemic heart disease (Miller et al., 1975), refractory heart failure (Guiha et al., 1974), mitral regurgitation and stenosis (Goodman et al., 1974; Bolen et al., 1975), and cardiomyopathy (Rossen et al., 1976). Benefit from impedance reduction has also been claimed in patients who have undergone cardiac surgical operations, particularly in those with high systemic vascular impedance, raised left atrial pressure, or suspected subendocardial ischaemia. In such circumstances, Stinson et al. (1975) compared several vasodilators: intravenous nitroprusside produced a more favourable haemodynamic response than chlorpromazine, nitroglycerin, or trimetaphan.

Salbutamol is a relatively specific $\beta_{2}$-adrenergic receptor agonist and causes peripheral vasodilatation. The haemodynamic effects of a single intravenous dose have been reported in normal persons (Warrell et al., 1970; Leitch et al., 1976) and in patients with respiratory disease (Warrell et al., 1970; Leitch et al., 1976), myocardial infarction (Lal et al., 1972), or mitral regurgitation (Gibson and Coltart, 1970). Salbutamol has also been ad-

'Present address: Cardiothoracic Institute, 2 Beaumont Street, London W1N 2DX.

Received for publication 24 January 1977 vocated for use after cardiac operations. Yacoub and Boyland (1973) reported the effects of a single intravenous dose and Wyse et al. (1974) compared the effects of continuous intravenous infusions of salbutamol and isoprenaline but gave no details of the basal haemodynamic state of their patients before administration of the drug.

The present study was undertaken to measure the haemodynamic changes during a continuous intravenous infusion of salbutamol in patients soon after cardiac operations. A comparison was made with the effects of an infusion of nitroprusside because this drug has previously been recommended in similar circumstances (Stinson et al., 1975).

\section{Methods}

Nine patients ( 7 male, 2 female; age range 36 to 64 years, mean 51 years) were studied. Five had aortocoronary bypass grafts inserted and 2 had had aortic and 2 mitral valve replacement. The patients were unselected consecutive surgical candidates in whom preoperative catheterisation had excluded left ventricular dyskinesia or valve disease other than that for which the operation was being performed. The exact nature of the investigation was explained to the patients in order to obtain informed consent.

The study began 24 to 36 hours after operation, at a time when the patients could be maintained for several hours in quiet undisturbed circumstances. During this period no additional drugs were given. One patient was receiving an inotropic agent (iso- 
prenaline $1 \mu \mathrm{g} / \mathrm{min}$ ) and this was continued at constant rate throughout the study. Nitroprusside or salbutamol was diluted in 5 per cent dextrose and administered by infusion pump (Sage Instruments, Model 242) through a cannula in the internal jugular vein. Nitroprusside was prepared in the pharmacy of St. Thomas's Hospital.

After a control period of 20 minutes, during which the haemodynamic variables listed in Table 1 were required to be constant, nitroprusside was given. The infusion rate was adjusted to bring about a fall of mean left atrial pressure and a reduction of systemic vascular resistance of approximately 30 per cent. Systolic blood pressure was not permitted to fall below $80 \mathrm{mmHg}$ or mean left atrial pressure below zero. The infusion was terminated if the heart rate rose above 135 beats $/ \mathrm{min}$. The dose varied between 50 and $100 \mu \mathrm{g} / \mathrm{min}$. The infusion was maintained at constant rate for 15 minutes; after discontinuing the infusion, measurements were continued for a further 20 minutes. The values for the haemodynamic variables at the end of the infusion were compared with the means of those at the end of the initial control periods and those after 20 minutes off nitroprusside.

When the patient had again remained haemodynamically stable for 20 minutes, salbutamol was infused in a dose of $15 \mu \mathrm{g} / \mathrm{min}$ (8 patients) or $30 \mu \mathrm{g} / \mathrm{min}$ (1 patient) and continued for 45 minutes. Measurements at the end of this period were compared with those in the control period. Nitroprusside was always administered before salbutamol because it has a short clinical half-life (approximately one minute) whereas the effects of salbutamol last for several hours.

Aortic blood flow was measured with a precalibrated extractable electromagnetic blood flow probe (Carolina Medical Electronics, 900 Series). It was placed firmly around the aorta, 1 to $2 \mathrm{~cm}$ above the sinotubular junction, at the time of operation and maintained in position by a nylon snare. The end was brought out through the chest wall. Release of the snare and gentle traction enabled the probe to be removed (Williams et al., 1972). The probe was connected to a flow meter (Carolina Medical Electronics, Model 601D).

Left atrial pressure was measured with a transducer (Statham 23P) connected to a fluid-filled line inserted in the left atrium at the time of operation. The reference level for pressure measurements was the sternal angle. Arterial pressure was measured with a Millar PC 350 catheter-tip micromanometer connected to a cannula in the radial or femoral artery. Arterial pressure and aortic flow signals, with simultaneous electrocardiogram, were processed 'on-line' by a small analogue computer
(Bourne and Williams, 1975), recorded on tape (Philips, Analog 7 FM) and displayed on an oscilloscope. Heart rate, arterial and left atrial pressures, stroke volume, stroke work, and systemic vascular resistance were monitored continuously. Maximum rate of change of power and maximum acceleration of flow from the left ventricle during ejection were calculated by integration and differentiation of the pressure and flow signals (Stein and Sabbah, 1976). Any delay between the pressure and flow signals was eliminated by superimposition of the initial rise of both variables.

Results are expressed as mean $\pm S E M$ and were compared using Student's paired $t$ test.

\section{Results}

The haemodynamic consequences of an infusion of nitroprusside and of salbutamol are illustrated in the Figure. Nitroprusside has a rapid onset of action which quickly subsides after withdrawal of the drug. By contrast the effects of salbutamol appear more slowly and persist for many minutes after the infusion has ceased. The pooled results are shown in Tables 1 and 2.

Salbutamol (Table 1) increased the cardiac index, but this was entirely attributable to a rise in heart rate and not to a change of stroke volume. Heart rate rose by a mean of 17 beats/minute. In 2 patients, neither of whom was the shortest or lightest in the group, the infusion of $15 \mu \mathrm{g} / \mathrm{min}$ was discontinued after 25 minutes when the heart rate rose above 135 beats $/ \mathrm{min}$. Systemic vascular resistance fell by 21 per cent and left atrial pressure by 40 per cent. Maximum acceleration of flow and maximum rate of change of power were both augmented.

Nitroprusside (Table 2) caused similar changes. The control values before the infusion of either drug were the same (Tables 1 and 2). Both drugs reduced the systemic vascular resistance and left atrial pressure, and neither increased the stroke index. However, there were important differences. The increase in heart rate with salbutamol (17 beats/min) was greater than with nitroprusside (6 beats $/ \mathrm{min})(P<0.01)$. Maximum acceleration of flow rose with salbutamol but not with nitroprusside $(P<0 \cdot 05)$. Salbutamol increased the maximum rate of change of power whereas nitroprusside had the reverse effect $(P<0.01)$.

\section{Discussion}

After heart operations the management of patients with cardiovascular disturbances such as low cardiac output, peripheral constriction, raised left 


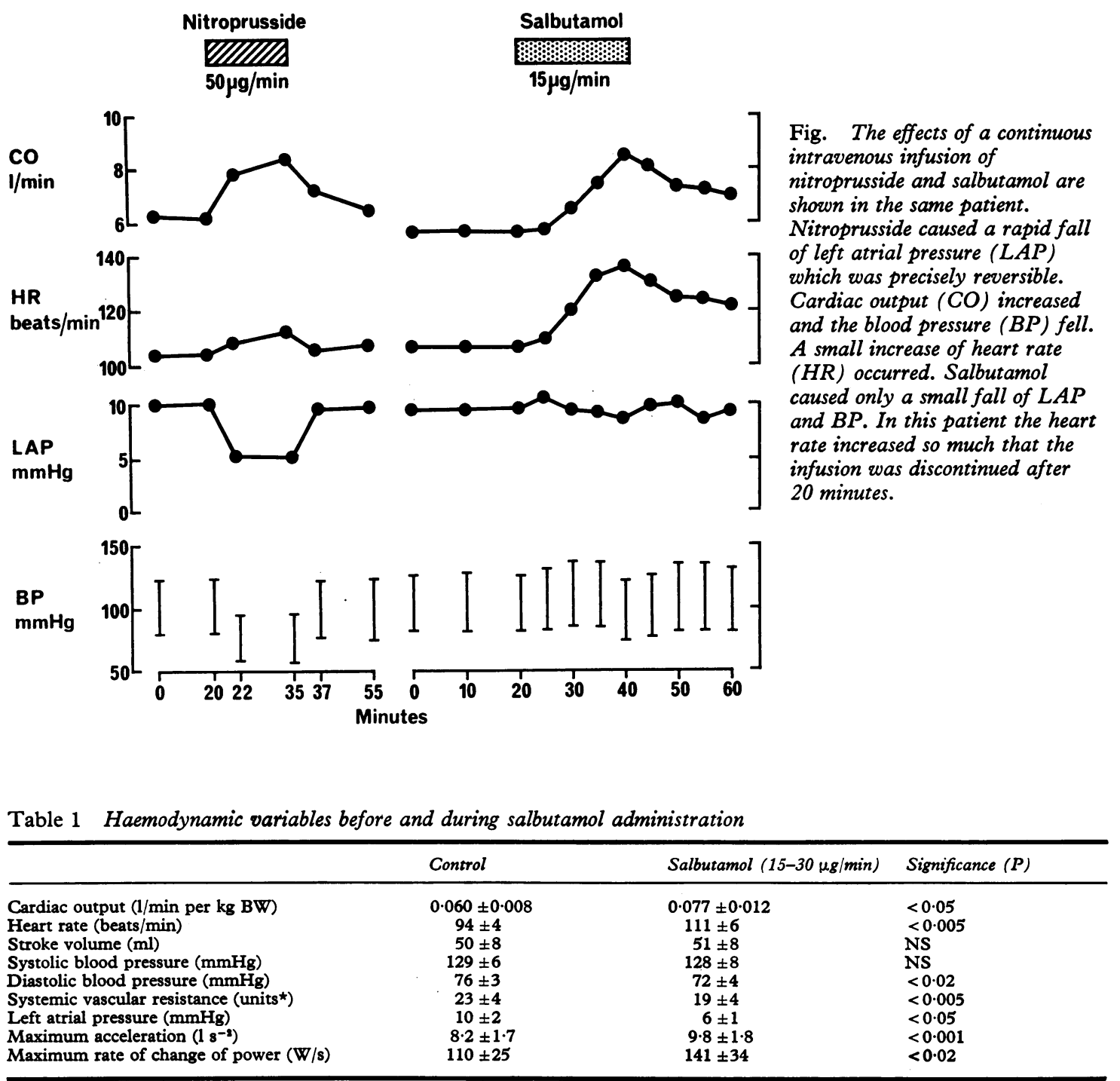

\#Systemic vascular resistance (in arbitrary units) expressed as mean systemic arterial pressure (mmHg)/cardiac output ( $1 / \mathrm{min}$ ). $\mathrm{BW}=$ body weight.

Table 2 Haemodynamic variables before and during nitroprusside administration

\begin{tabular}{|c|c|c|c|}
\hline & Control & Nitroprusside $(50-100 \mu \mathrm{g} / \mathrm{min})$ & Significance $(P)$ \\
\hline $\begin{array}{l}\text { Cardiac output }(1 / \mathrm{min} \text { per } \mathrm{kg} \mathrm{BW}) \\
\text { Heart rate (beats/min) } \\
\text { Stroke volume (ml) } \\
\text { Systolic blood pressure (mmHg) } \\
\text { Diastolic blood pressure (mmHg) } \\
\text { Systemic vascular resistance (units) } \\
\text { Left atrial pressure (mmHg) } \\
\text { Maximum acceleration }\left(1 \mathrm{~s}^{-2}\right) \\
\text { Maximum rate of change of power }(\mathrm{W} / \mathrm{s})\end{array}$ & $\begin{aligned} 0.064 & \pm 0 \cdot 010 \\
98 & \pm 4 \\
50 & \pm 7 \\
132 & \pm 6 \\
76 & \pm 3 \\
23 & \pm 3 \\
9 & \pm 2 \\
8 \cdot 5 & \pm 1 \\
135 & \pm 30\end{aligned}$ & $\begin{aligned} 0.071 & \pm 0 \cdot 010 \\
104 & \pm 5 \\
52 & \pm 8 \\
111 & \pm 8 \\
67 & \pm 3 \\
16 & \pm 1 \\
5 & \pm 1 \\
8 \cdot 9 & \pm 1 \\
100 & \pm 20\end{aligned}$ & $\begin{array}{l}<0.05 \\
<0.005 \\
\text { NS } \\
<0.005 \\
<0.005 \\
<0.005 \\
<0.01 \\
\text { NS } \\
<0.02\end{array}$ \\
\hline
\end{tabular}


atrial pressure, or subendocardial ischaemia, is complex. Inotropic drugs such as isoprenaline are much used for some of these complications but their use has been criticised because the oxygen consumption of the myocardium is increased and pre-existing ischaemia may be increased (Maroko et al., 1971). The reduction of systemic vascular impedance or left ventricular afterload by drugs which act as vasodilators is an alternative form of treatment. This has been shown to be beneficial in myocardial infarction (Chatterjee et al., 1973), chronic heart failure (Guiha et al., 1974; Miller et al., 1975), and mitral valve disease (Goodman et al., 1974; Bolen et al., 1975). Such results, however, should not immediately be applied to other clinical situations since the overall haemodynamic response to such treatment is dependent on the pre-existing conditions, the pharmacological properties of the particular drug, the dose of the drug, the site of action, and reflex changes. Vasodilators may be advantageous to the myocardium for several reasons: reduction of systemic vascular impedance permits greater muscle shortening and reduces systolic left ventricular wall tension and left ventricular enddiastolic volume; a fall of left atrial pressure resulting from a venodilator effect reduces left ventricular end-diastolic volume, and in addition encourages greater blood flow in the subendocardial tissue during diastole, and may thus relieve pre-existing ischaemia in the subendocardial myocardium; a direct action of vasodilators on the coronary vasculature has been reported and blood flow to ischaemic segments of muscle may increase (Goldstein et al., 1974). These many effects tend to result in a favourable change in the balance of oxygen supply and demand, but because of the complexity of the interactions among these and other factors, new drugs should be evaluated in each clinical situation in which they might be used. Nitroprusside has been advocated for use after cardiac operations (Stinson et al., 1975), and our study was designed to compare nitroprusside and salbutamol in this clinical situation.

Salbutamol and nitroprusside both acted as vasodilators (Tables 1 and 2 ) and in the doses chosen the changes in systemic vascular resistance and in left atrial pressure were similar. However, salbutamol caused a substantially greater increase in heart rate, and stroke volume was unaltered by either drug. This effect might sometimes be beneficial but in general is detrimental since heart rate is an important determinant of oxygen consumption (Braunwald, 1971). This increase in heart rate with salbutamol occurs also in normal persons and in patients with respiratory failure (Warrell et al., 1970; Leitch et al., 1976). Oxygen consumption of the myocardium is increased further by salbutamol because of the increase in maximum acceleration of flow $(20 \%)$ and maximum rate of change of power $(28 \%)$. Maximum acceleration was unaffected by nitroprusside and maximum rate of change of power diminished $(25 \%)$. Since stroke volume was unaltered and preload and afterload equally affected by the two drugs, these differences might be explained if salbutamol increased contractility in association with the greater change of heart ratethe Bowditch effect (Bowditch, 1871). Whatever the explanation, an increase in the maximum rate of change of power and heart rate are both expected to increase myocardial oxygen consumption. For these reasons and because the long duration of action of salbutamol does not allow precise control of the infusion, nitroprusside is the preferred drug.

The equipment used in this study was funded by the Endowments (Research) Fund of St. Thomas's Hospital. The analogue computer for bedside monitoring was constructed by the Medical Electronics Department of St. Thomas's Hospital. We are grateful to Allen and Hanbury's Ltd. for a supply of salbutamol.

\section{References}

Bolen, J. L., Lopes, M. G., Harrison, D. C., and Alderman, E. L. (1975). Analysis of left ventricular function in response to afterload changes in patients with mitral stenosis. Circulation, 52, 894-900.

Bourne, P. R., and Williams, B. T. (1975). A cardiac monitor combining flow and pressure measurement. Biomedical Engineering, 10, 453-455.

Bowditch, H. P. (1871). Úber die Eigenthümlichkeiten der Reizbarkeit, welche die Muskelfasern des Herzens zeigen. Bericht über die Verhandlungen der Sächsischen Akademie der Wissenschaften zu Leipzig (Math. Phys. Kl.), 23, 652.

Braunwald, E. (1971). Control of myocardial oxygen consumption: physiologic and clinical considerations. American fournal of Cardiology, 27, 416-432.

Chatterjee, K., Parmley, W. W., Ganz, W., Forrester, J., Walinsky, P., Crexells, C., and Swan, H. J. C. (1973). Hemodynamic and metabolic responses to vasodilator therapy in acute myocardial infarction. Circulation, 48, 1183-1193.

Gibson, D. G., and Coltart, D. J. (1970). Haemodynamic effects of intravenous solbutamol in patients with mitral valve disease: comparison with isoprenaline and atropine. Postgraduate Medical fournal, 47, Suppl. (March), 40-44.

Goldstein, R. E., Stinson, E. B., Scherer, J. L., Seningen, R. P., Grehl, T. M., and Epstein, S. E. (1974). Intraoperative coronary collateral function in patients with coronary occlusive disease: nitroglycerin responsiveness and angiographic correlations. Circulation, 49, 298-308.

Goodman, D. J., Rossen, R. M., Holloway, E. L., Alderman, E. L., and Harrison, D. C. (1974). Effect of nitroprusside on left ventricular dynamics in mitral regurgitation. Circulation, 50, 1025-1032.

Guiha, N. H., Cohn, J. N., Mikulic, E., Franciosa, J. A., and Limas, C. J. (1974). Treatment of refractory heart failure with infusion of nitroprusside. New England fournal of Medicine, 291, 587-592. 
Lal, S., Savidge, R. S., Davies, D. M., Ali, M. M., and Soni, V. (1972). Intravenous salbutamol and cardiogenic shock. Lancet, 1, 853-854.

Leitch, A. G., Clancy, L. J., Costello, J. F., and Flenley, D. C. (1976). Effect of intravenous infusion of salbutamol on ventilatory response to carbon dioxide and hypoxia and on heart rate and plasma potassium in normal men. British Medical fournal, 1, 365-367.

Maroko, P. R., Kjekshus, J. K., Sobel, B. E., Watanabe, T., Covell, J. W., Ross, J., and Braunwald, E. (1971). Factors influencing infarct size following experimental coronary artery occlusions. Circulation, 43, 67-82.

Miller, R. R., Vismara, L. A., Zelis, R., Amsterdam, E. A., and Mason, D. T. (1975). Clinical use of sodium nitroprusside in chronic ischemic heart disease: effects on peripheral vascular resistance and venous tone and on ventricular volume, pump and mechanical performance. Circulation, 51, 328-336.

Rossen, R. M., Alderman, E. L., and Harrison, D. C. (1976). Circulatory response to vasodilator therapy in congestive cardiomyopathy. British Heart fournal, 38, 695-700.

Stein, P. D., and Sabbah, H. N. (1976). Ventricular performance measured during ejection: studies in patients of the rate of change of ventricular power. American Heart fournal, 91, 599-606.

Stinson, E. B., Holloway, E. L., Derby, G., Oyer, P. E., Hollingsworth, J., Griepp, R. B., and Harrison, D. C. (1975). Comparative hemodynamic responses to chlorpro- mazine, nitroprusside, nitroglycerin, and trimethaphan immediately after open-heart operations. Circulation, 51-52, Suppl. I, I-26-33.

Warrell, D. A., Robertson, D. G., Newton Howes, J., Conolly, M. E., Paterson, J. W., Beilin, L. J., and Dollery, C. T. (1970). Comparison of cardiorespiratory effects of isoprenaline and salbutamol in patients with bronchial asthma. British Medical fournal, 1, 65-70.

Williams, B. T., Sancho-Fornos, S., Clarke, D. B., Abrams, L. D., Schenk, W. G., Jr., and Barefoot, C. A. (1972). The Williams-Barefoot extractable blood flow probe: design, transducer characteristics, and clinical application in cardiac surgery. Fournal of Thoracic and Cardiovascular Surgery, 63, 917-921.

Wyse, S. D., Gibson, D. G., and Branthwaite, M. A. (1974). Haemodynamic effects of salbutamol in patients needing circulatory support after open-heart surgery. British Medical fournal, 3, 502-503.

Yacoub, M. H., and Boyland, E. (1973). Cardiovascular effects of intravenous salbutamol after open heart operations. Lancet, 1, 1260-1261.

Requests for reprints to Dr. P. A. Poole-Wilson, Cardiothoracic Institute, 2 Beaumont Street, London W1N 2DX. 